\title{
Developmental Behavioral Pediatrician
}

National Cancer Institute

\section{Source}

National Cancer Institute. Developmental Behavioral Pediatrician. NCI Thesaurus. Code C147461.

A pediatrician who specializes in diagnosing and treating developmental and behavioral disorders in children. 